University of Wollongong

Research Online

Faculty of Engineering and Information

Faculty of Engineering and Information

Sciences - Papers: Part B

Sciences

2019

\title{
A novel design of flow structure model for online viscosity measurement
}

Yu Bie

Kunming University of Science and Technology

Xiyan Guo

Kunming University of Science and Technology

Pengyun Song

Kunming University of Science and Technology

Jian Yang

University of Nottingham Ningbo China

Zhixiong $\mathrm{Li}$

University of Wollongong, Ocean University of China, lizhixio@uow.edu.au

Follow this and additional works at: https://ro.uow.edu.au/eispapers1

Part of the Engineering Commons, and the Science and Technology Studies Commons

Research Online is the open access institutional repository for the University of Wollongong. For further information contact the UOW Library: research-pubs@uow.edu.au 


\title{
A novel design of flow structure model for online viscosity measurement
}

\begin{abstract}
In industry, viscosity is widely used to assess the level of internal friction in a fluid in order to evaluate lubricant oil performance. Various sensing equipment has been developed to measure viscosity, either offline or online. However, most offline methods weaken the rheological behaviour of the fluid, resulting in inaccurate measurements. Online monitoring can overcome this limitation but viscosity measurements at real-time temperatures still cannot be directly converted to viscosities at the standard temperatures in ISO 3448. Consideration of the effect of temperature in transferring real-time viscosity measurement into the ISO standard presents a challenge. To bridge this research gap, this paper proposes a novel flow structure for online viscosity measurement by considering the effect of temperature. In order to eliminate the friction-heat effect and turbulent flow of the fluid, the structure parameters (such as flow diameter and heat transfer area) of the new viscosity sensing device are optimised by computational fluid dynamics (CFD) analysis using ANSYS/fluent simulations. The optimisation results demonstrate a linear relationship between the outlet, the inlet and the environmental temperatures of the designed flow structure under laminar flow. As a result, the outlet temperature can be controlled to obtain the viscositytemperature characteristics of the lubricant oil using an online approach. In this way, the real-time viscosity measurement can be converted into the ISO standard to achieve effective online viscosity monitoring.

Disciplines

Engineering | Science and Technology Studies

\section{Publication Details}

Bie, Y., Guo, X., Song, P., Yang, J. \& Li, Z. (2019). A novel design of flow structure model for online viscosity measurement. Insight: Non-Destructive Testing and Condition Monitoring, 61 (1), 9-14.
\end{abstract}




\title{
A novel design of flow structure model for online viscosity measurement
}

\author{
Yu Bie, Xiyan Guo, Pengyun Song, Jian Yang and Zhixiong Li
}

\begin{abstract}
In industry, viscosity is widely used to assess the level of internal friction in a fluid in order to evaluate lubricant oil performance. Various sensing equipment has been developed to measure viscosity, either offline or online. However, most offline methods weaken the rheological behaviour of the fluid, resulting in inaccurate measurements. Online monitoring can overcome this limitation but viscosity measurements at real-time temperatures still cannot be directly

converted to viscosities at the standard temperatures in ISO 3448. Consideration of the effect of temperature in transferring real-time viscosity measurement into the ISO standard presents a challenge. To bridge this research gap, this paper proposes a novel flow structure for online viscosity measurement by considering the effect of temperature. In order to eliminate the friction-heat effect and turbulent flow of the fluid, the structure parameters (such as flow diameter and heat transfer area) of the new viscosity sensing device are optimised by computational fluid dynamics (CFD) analysis using ANSYS/fluent simulations. The optimisation results demonstrate a linear relationship between the outlet, the inlet and the environmental temperatures of the designed flow structure under laminar flow. As a result, the outlet temperature can be controlled to obtain the viscosity-temperature characteristics of the lubricant oil using an online approach. In this way, the real-time viscosity measurement can be converted into the ISO standard to achieve effective online viscosity monitoring.
\end{abstract}

Keywords: viscosity monitoring, flow structure, online measurement, sensing device.

\section{Introduction}

Condition monitoring and fault diagnosis (CMFD) are effective tools for detecting unexpected failures in machines and, hence, preventing catastrophic accidents ${ }^{[1,2]}$. Lubrication failure is one of the main reasons for frictional wear in mechanical equipment ${ }^{[3,4]}$. Direct contact between the frictional parts due to fracture of the lubricant oil film accelerates the friction and wear, resulting in machine damage. Furthermore, degradation of the lubricant oil may decrease the oil film thickness or even break the film, leading to an increase in the friction ${ }^{[5]}$. It is therefore important to evaluate lubricant oil performance.

The viscosity is the most widely used parameter for evaluating lubricant oil performance. It is of great importance to be able to perform accurate measurement of the viscosity for the evaluation of oil performance in different applications ${ }^{[6]}$. Viscosity sensing methods can be categorised into offline and online methods. Popular offline methods include capillary viscometry ${ }^{[7,8]}$ and falling ball viscometry ${ }^{[9-12]}$. Although the offline methods are easy to apply, the measurement accuracy depends on manual operation. In addition, the rheological behaviour of the fluid cannot be easily included in the offline measuring process. Online methods, such as vibration viscometry ${ }^{[13,14]}$ and rotating viscometry ${ }^{[1,17]}$, are able to measure the fluid viscosity without destroying the rheological behaviour of the fluid. For example, Etchart et al ${ }^{[17]}$ successfully measured the viscosity of a fluid with obvious rheological behaviour using vibration viscometry, Janeiro et al ${ }^{[18]}$ used vibration viscometry to achieve fluid impedance spectroscopy and Diogo et al ${ }^{[19]}$ utilised vibration viscometry to measure fluid viscosity with different chemical components and temperatures. Previous research has found that fluid viscosity is sensitive to the measurement environment, so the temperature and pressure of the fluid flow should be taken into account in the measuring process ${ }^{[20]}$.
Lv et $a l^{[21]}$ suggested that, in a micro-crevice environment, fluid conditions such as temperature should be included in the viscosity calculation to make the measurement more credible. Zambrano et al ${ }^{[22]}$ compared viscosity measurements using vibration viscometry and a falling body viscometer in order to obtain reliable fluid viscosity measurements under high-pressure conditions. Li and $\mathrm{Zhao}^{[23]}$ investigated the effect of temperature in the viscosity measurement of space lubricant oil using a capillary viscometer. The analysis result showed that temperatures other than just the ISO standard temperatures $\left(40^{\circ} \mathrm{C} \text { or } 100^{\circ} \mathrm{C}\right)^{[24]}$ should be considered in the viscosity measurement.

Through a review of the literature it can be seen that offline methods for viscosity measurement may be subject to the rheological behaviour of the fluid; in other words, the time delay before measuring the collected oil samples may change the fluid flow conditions and eventually make the viscosity measurement inaccurate ${ }^{[25]}$. Moreover, offline measurement may require too much

\section{Submitted 17.06.18 / Accepted 27.11.18}

Yu Bie, Xiyan Guo and Pengyun Song are with the Faculty of Chemical Engineering, Kunming University of Science and Technology, Kunming 650500, P R China.

Jian Yang is with the Department of Mechanical, Materials and Manufacturing Engineering, University of Nottingham Ningbo China, Ningbo 315100, China.

Zhixiong Li* is with the School of Engineering, Ocean University of China, Qingdao 266100, China, as well as the School of Mechanical, Materials, Mechatronic and Biomedical Engineering, University of Wollongong, Wollongong, New South Wales 2522, Australia.

*Corresponding author. Email:zhixiong.li@ieee.org 
time and too many oil samples. Online measurement of viscosity can overcome these limitations, but viscosity measurements at realtime temperatures cannot be directly compared with ISO standard values $^{[24]}$. This is because ISO 3448 determines standard viscosity values using a reference temperature of $40^{\circ} \mathrm{C}$, while the real-time fluid temperature in online monitoring will not be exactly $40^{\circ} \mathrm{C}$. If the viscosity measured online cannot be converted into the ISO standard value, it is very difficult to evaluate the performance of the lubricant oil, let alone to assess the health condition of the machine. However, existing viscosity sensing devices seldom take the effect of temperature into consideration, while conversion between realtime viscosity measurements and the ISO standard value remains an unsolved problem.

To address the aforementioned challenge, this paper proposes a novel flow structure for online viscosity measurement that takes the effect of temperature into consideration. In order to convert the online measurement to the ISO standard value, an automatic heater module is designed for the proposed flow structure to create a constant temperature environment to calculate the viscositytemperature characteristics of the lubricant oil. Then, the realtime viscosity can be fitted for comparison with the ISO standard. Moreover, in order to eliminate friction-heat and turbulent effects during the measuring process, the structure parameters of the flow pass are optimised using computational fluid dynamics (CFD) analysis to maintain the fluid in the condition of laminar flow. Numerical simulations demonstrate the effectiveness of the presented flow structure for online viscosity monitoring. This paper may provide a theoretical basis for the development of online viscosity measuring equipment.

\section{The proposed viscosity measuring device}

\subsection{Design principle}

Viscosity is defined as the quantity describing the magnitude of the internal friction in fluids. The fluid viscosity is the friction caused by adjacent layers moving with different speeds. When the fluid flows through a tube, the lowest viscous resistance is in the centre of the tube while the highest resistance is at the sides of the tube. Subject to the fluid viscous resistance and friction in the tube wall, the velocity of the layer of fluid at the tube wall is zero (under the assumption of no slippage).

In a general parallel flow, such as in a straight pipe, the shear stress is proportional to the velocity gradient. If the velocity in the central layer of the tube is constant, the relationship between shear stress and viscosity can be expressed as:

$$
\tau=\mu \frac{\partial u}{\partial y}
$$

where $\tau$ is the shear stress, $\mu$ is the viscosity of the fluid, $u$ is the fluid velocity and $\frac{\partial u}{\partial y}$ is the gradient of this velocity in the $y$ direction. Considering the influence of the effect of temperature on the fluid flow, the Reynolds number is adopted:

$$
R_{e}=\frac{\rho u L}{\mu}
$$

where $R_{e}$ is the Reynolds number, $\rho$ is the density and $L$ is the length of the tube.

The viscosity measuring equipment is designed based on the definition of viscosity, as shown in Figure 1. By controlling the velocity of the fluid to keep it in the condition of laminar flow (ie the gradient of velocity is a constant), the shear stress will be proportional to the viscosity of the fluid. Hence, under laminar flow the shear stress can be measured to determine the corresponding viscosity.

\subsection{Operational principle of viscosity measuring equipment}

The design of the viscosity measurement equipment is shown in Figure 2. The operating principle is explained as follows: The liquid first enters the velocity-controlled pump. A cooling system is then used to control the fluid temperature. After the fluid enters into the measurement tube, a controllable heater is applied to the fluid to measure the fluid stress at ISO standard temperatures such as $40^{\circ} \mathrm{C}$. As a result, if the fluid velocity and temperature are controlled as constants in the inlet of the designed device, the relationship between the inlet velocity and temperature and the output standard viscosity can be established. Subsequently, in online monitoring, the cooling system and controllable heater are shut off and the realtime viscosity measurement can be fitted to the ISO standard value based on the established relationship between the inlet velocity and temperature and the output standard viscosity.

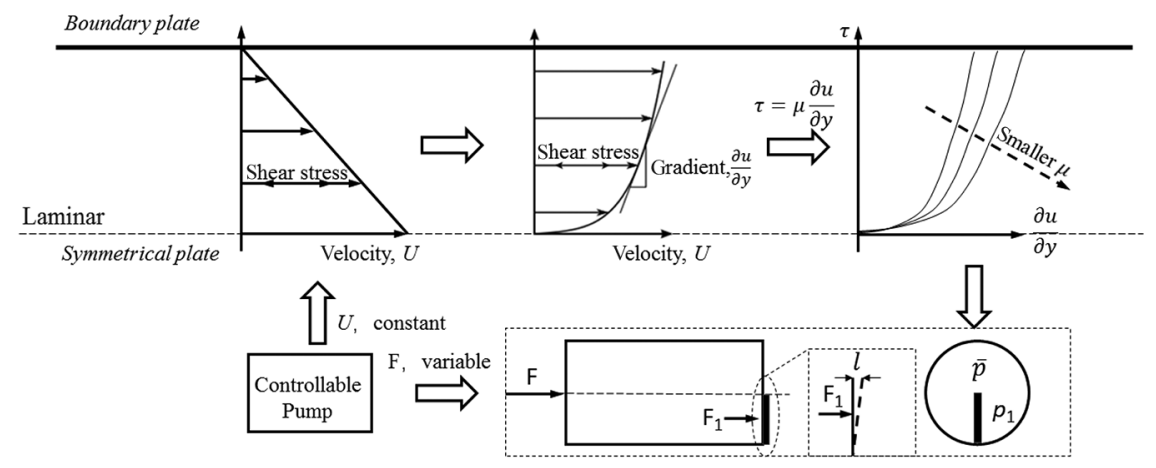

Figure 1. Principle of viscosity measurement

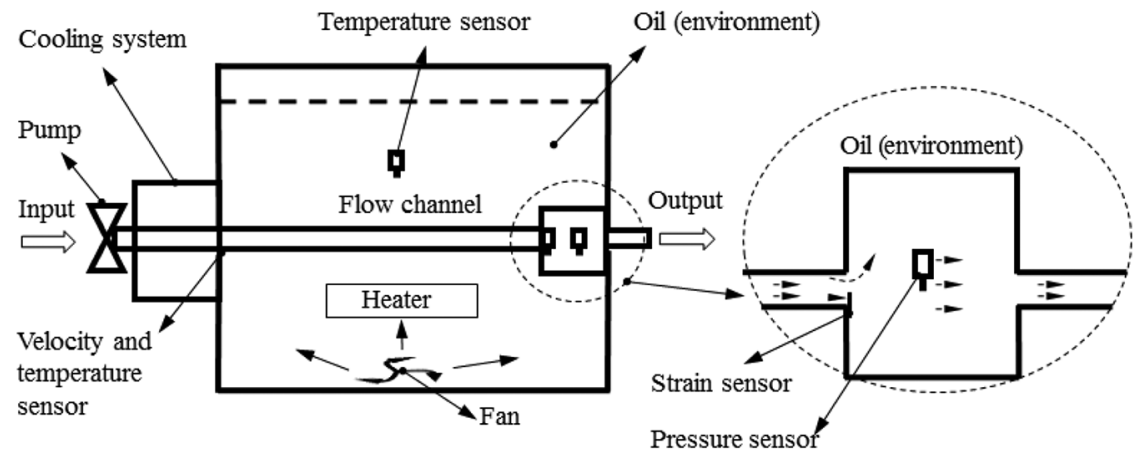

Figure 2. Schematic illustration of the online viscosity measuring equipment

\section{Simulation results and discussions}

A simulation model of the measuring device proposed in Figure 2 was established using computational fluid dynamics (CFD) analysis to investigate the influence of the effect of temperature on the fluid flow. The cooling system in the proposed device is not only 
able to control the temperature of the inlet fluid flow but also to stabilise the temperature to guarantee the accuracy of the viscosity measurement. As a result, an investigation into the viscositytemperature characteristics and the effect of temperature on the fluid characteristics can be carried out.

\subsection{Design of flow tube}

The design goal of the flow tube is to ensure that the fluid flow can be controlled into the laminar flow condition and at the measuring point the flow temperature can be controlled to the required value. Therefore, a spiral (helical) tube was adopted in the simulation. Because in practice the fluid is always non-Newtonian, an inside groove at the rear end of the tube was created as a buffer to small variations in the fluid velocity. A pressure sensor was installed in the middle of the groove to measure the fluid viscosity. In order to realise constant velocity of the fluid flow in the tube, the correct spiral radius and spiral number need to be determined. For this purpose, factor analysis design was employed to determine the tube parameters. Tables 1 and 2 list the design factors in the simulations. In the factor analysis, the simulation model was defined as D-T-R, where $\mathrm{D}$ denotes the tube diameter, $\mathrm{T}$ denotes the spiral number and $\mathrm{R}$ denotes the spiral radius. For example, model D6-T5-R30 was simulated with a $6 \mathrm{~mm}$ tube diameter, five spiral turns and a $30 \mathrm{~mm}$ spiral radius.

Table 1. Design factors for spiral radius, spiral diameter, spiral turn number and flow velocity

\begin{tabular}{|c|c|c|c|c|}
\hline \multicolumn{1}{|c|}{ Factors } \\
\hline Spiral radius $(\mathrm{mm})$ & 30 & 40 & 50 & - \\
\hline Spiral number (turns) & 3 & 5 & - & - \\
\hline Flow velocity $(\mathrm{m} / \mathrm{s})$ & 1 & 20 & 40 & 60 \\
\hline Tube diameter $(\mathrm{mm})$ & 6 & 8 & 10 & 12 \\
\hline
\end{tabular}

Table 2. Inlet and ambient temperatures

\begin{tabular}{|c|c|c|c|c|c|}
\hline Inlet temperature $\left({ }^{\circ} \mathrm{C}\right)$ & 0 & 10 & 20 & 30 & - \\
\hline Ambient temperature $\left({ }^{\circ} \mathrm{C}\right)$ & 40 & 60 & 80 & 100 & 200 \\
\hline
\end{tabular}

The finite element modelling approach ${ }^{[26-28]}$ was employed to establish the CFD simulation models. Taking model D6-T5-R30 as an example, its grid model, grid quality and boundary conditions are shown in Figure 3. A quadrilateral grid was used to partition the model into 526,973 elements. Considering the effect of laminar flow, five layers with hexagonal elements were added in the area close to the tube wall. The grid quality of the model was analysed to show that only $15.6 \%$ of the elements scored lower than 0.6 in terms of quality. As a result, the overall quality of the model was quite satisfactory to ensure calculation accuracy.

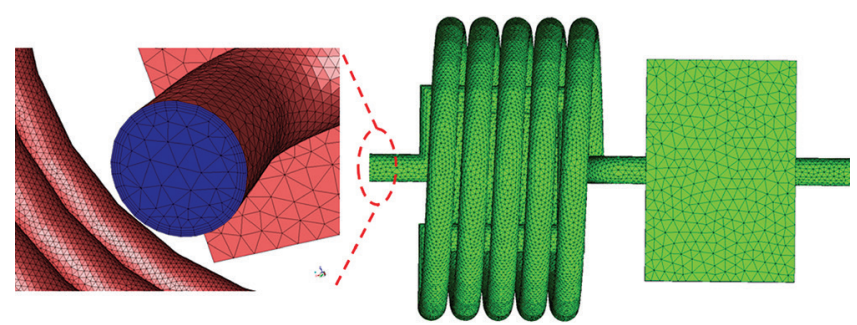

Figure 3. Grid model of the proposed device

Insight • Vol 61 • No 1 • January 2019

\subsection{Results and discussions}

The model simulations were implemented based on factor analysis design. Figure 4 shows the result of the calculations for model D6-T3-R30. In Figure 4, $T_{\text {out }}$ is the measured temperature at the junction of the circular tube and the square tube, $T_{\text {in }}$ is the inlet temperature and $T_{\text {wall }}$ is the ambient temperature (which can be controlled by the heater). As can been seen in Figure 4, the temperature distribution of $T_{\text {out }}$ is stabilised at around $28^{\circ} \mathrm{C}$, indicating the laminar flow condition. However, in this simulation the ISO standard $40^{\circ} \mathrm{C}$ was not reached at the outlet of the device. This is due to incorrect tube structure parameters. Hence, factor analysis was carried out to find the correct parameters.

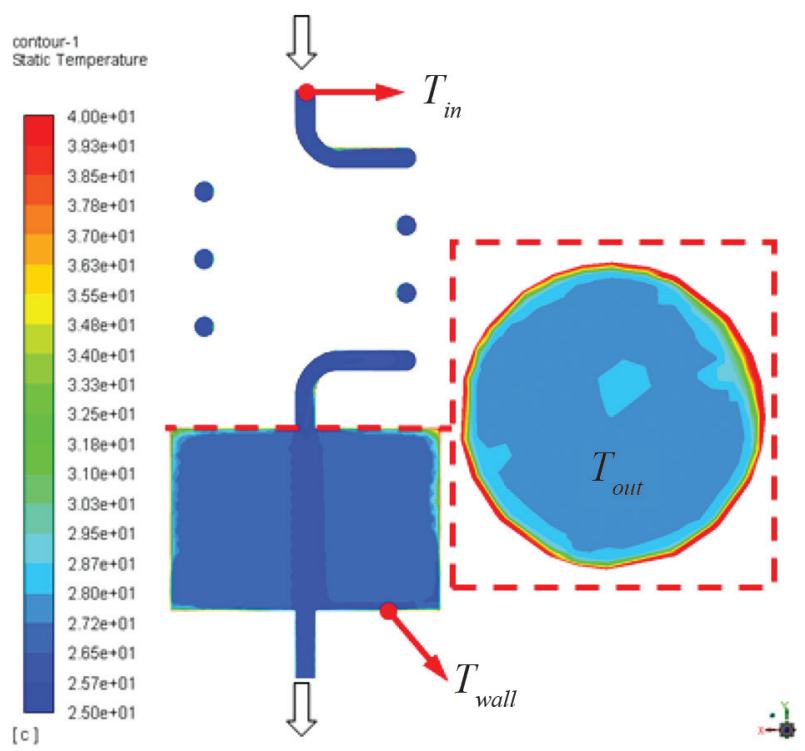

Figure 4. The definition of global temperature and measurement temperature for D6-T3-R60

The structure of the tube or flow pass was optimised based on the evaluation index of the heat transfer effect, the complexity of the heat transfer mechanism and the maximum inlet pressure. The parameter optimisation process is described in Figure 5.

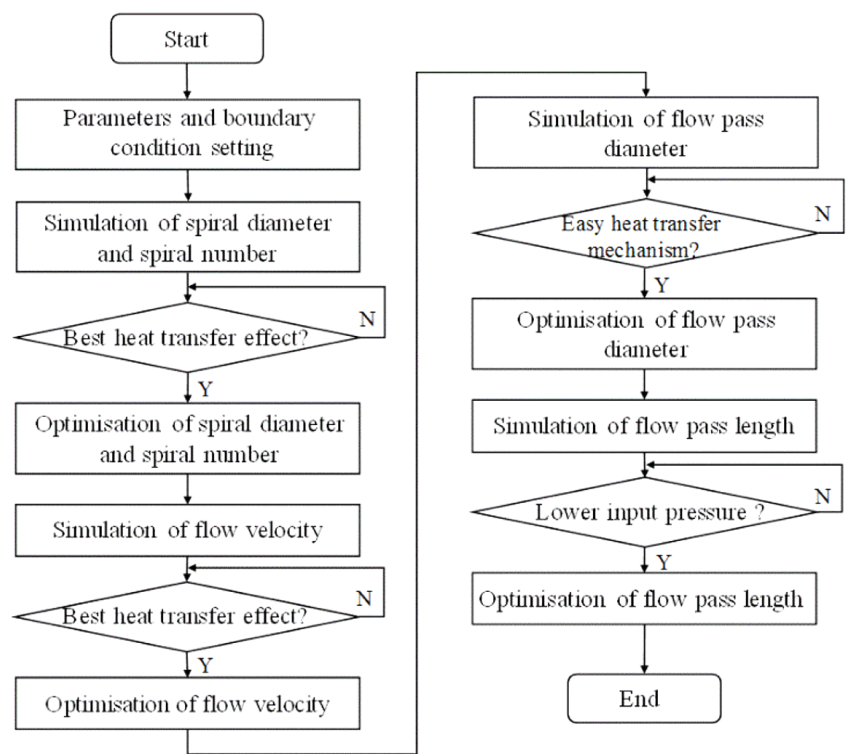

Figure 5. Block diagram of the tube structure optimisation process

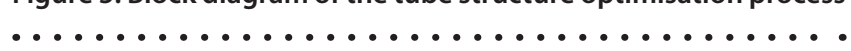




\subsubsection{The effect of spiral diameter and spiral number on measurement temperature}

The simulation results using different spiral radii and spiral numbers are displayed in Figure 6. The ambient temperature was $40^{\circ} \mathrm{C}$, the inlet temperature was $25^{\circ} \mathrm{C}$ and the tube flow diameter was $6 \mathrm{~mm}$. The simulations also cover the effects of flow velocities of $1 \mathrm{~m} / \mathrm{s}$, $20 \mathrm{~m} / \mathrm{s}, 40 \mathrm{~m} / \mathrm{s}$ and $60 \mathrm{~m} / \mathrm{s}$.

It can be seen from Figure 6 that the temperature distribution at the outlet basically remains consistent with different spiral radii and spiral numbers. The fluid temperature close to the tube wall is the highest. With the same flow velocity and spiral number, the average temperature at the outlet increases with an increase in the spiral radius, while with the same spiral number and spiral radius, the average temperature at the outlet decreases with an increase in the fluid velocity. These obtained temperature distribution results

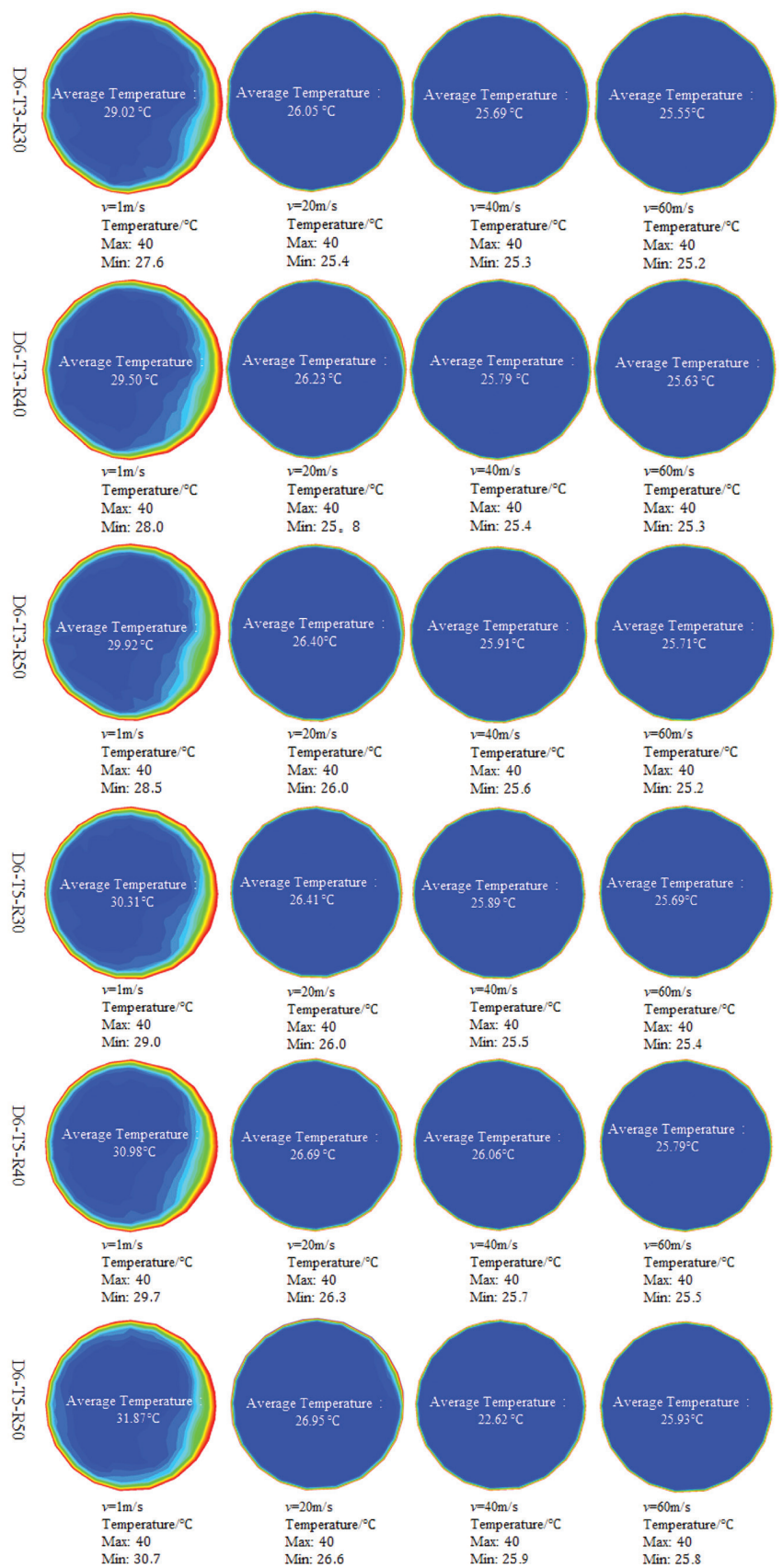

Figure 6. Calculated temperature results of D6-T3 and D6-T5 for different spiral radii conform to a common sense understanding of heat transfer theory. However, the effect of heat transfer is not distinct for the simulated models with high laminar flow velocity. Generally, with higher laminar flow velocity the heat transfer effect will be more obvious. The reason for this is probably due to improper matching between the designed parameter values. Because the proposed viscosity measuring device is based on laminar flow conditions in the tube, the flow velocity may significantly influence the measurement result. It should be noted that the obtained $T_{\text {out }}$ using D6-T5-R50 is the largest among other models in Figure 6. D6-T5-R50 was used to further investigate the laminar flow velocity effect.

\subsubsection{The effect of flow velocity on measurement temperature}

Based on the D6-T5-R50 model, the effect of laminar flow velocity was investigated. The calculation results using the D6-T5-R50 model for different velocities are shown in Figure 7, where a fitting function has been applied based on the calculation results. It can be seen from Figure 7 that, when the velocity is $0.1 \mathrm{~m} / \mathrm{s}, T_{\text {out }}$ is $38.33^{\circ} \mathrm{C}$; when the velocity is $0.5 \mathrm{~m} / \mathrm{s}, T_{\text {out }}$ is $33.60^{\circ} \mathrm{C}$, and, when the velocity is $1 \mathrm{~m} / \mathrm{s}, T_{\text {out }}$ is $31.87^{\circ} \mathrm{C}$. Therefore, in order to acquire a better heat transfer result, the fluid flow velocity should be selected as $0.1 \mathrm{~m} / \mathrm{s}$.

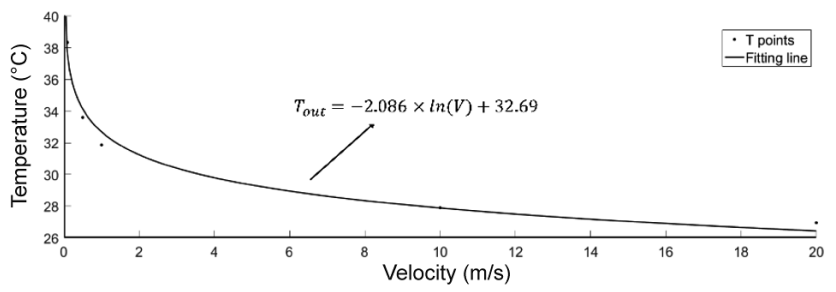

Figure 7. The calculated temperature results of D6-T5-R50 at different velocities

\subsubsection{The effect of tube diameter on measurement temperature}

Based on the preliminary optimisation results using the D6-T5-R50 model, the outlet temperature can reach $38.33^{\circ} \mathrm{C}$, ie very close to the ISO standard of $40^{\circ} \mathrm{C}$. However, in order to realise the desired standardisation of the online measurement using the proposed device, the tube diameter needed to be further optimised. To this end, simulations were performed using T5-R50 at $0.1 \mathrm{~m} / \mathrm{s}$ and $0.5 \mathrm{~m} / \mathrm{s}$, respectively. Figure 8 depicts the simulation results. The optimisation results show an optimal tube diameter to be $10 \mathrm{~mm}$. This is because the outlet temperature reached $35.31^{\circ} \mathrm{C}$, indicating quite a good heat transfer effect. More importantly, compared to other tube diameters used, a diameter of $10 \mathrm{~mm}$ allows more space for sensor installation.

As can be seen in Figure 8 , when the velocity is $0.1 \mathrm{~m} / \mathrm{s}$ a linear relationship (with a slope rate of $-0.745^{\circ} \mathrm{C} / \mathrm{mm}$ ) is observed between the tube diameter and the average outlet temperature. By contrast, when the velocity is $0.5 \mathrm{~m} / \mathrm{s}$ a quadratic polynomial fitting function is found between the tube diameter and the average outlet temperature. It should be noted that, with constant thermal conductivity and a constant area of thermal conductivity, the heat transfer quality is proportional to the temperature variation rate. Therefore, when the velocity is $0.5 \mathrm{~m} / \mathrm{s}$ the heat transfer mechanism is similar to natural convection and friction heating, which is not appropriate to describe the heat transfer in the designed tube. As a result, the optimal flow velocity was chosen to be $0.1 \mathrm{~m} / \mathrm{s}$ and the tube diameter used in this paper was $10 \mathrm{~mm}$. 


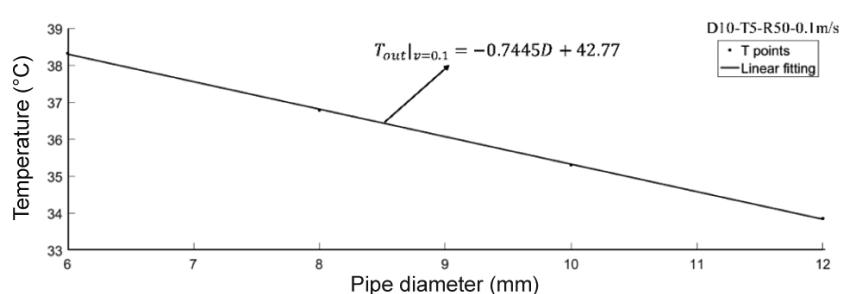

(a)

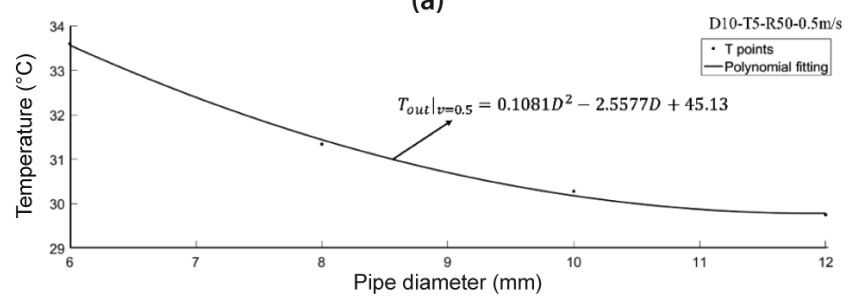

(b)

Figure 8. The calculated temperature of the D10-T5-R50 model when: (a) velocity is $0.1 \mathrm{~m} / \mathrm{s}$; and (b) velocity is $0.5 \mathrm{~m} / \mathrm{s}$

\subsubsection{The effect of tube length on measurement temperature}

Based on the parameter optimisation result, the D10-T5-R50 model with $0.1 \mathrm{~m} / \mathrm{s}$ velocity was selected. The outlet temperature was $35.31^{\circ} \mathrm{C}$. Considering the temperature difference $\left(4.69^{\circ} \mathrm{C}\right)$ from the ISO standard value of $40^{\circ} \mathrm{C}$, the tube structure needed to be optimised further in terms of thermal conductivity. Two tube types, namely U-type and double helix-type tubes, were considered (see Figure 9).
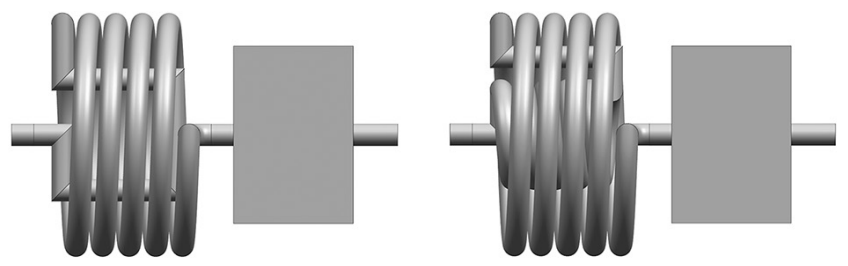

Figure 9. Structure of U-type tube (left) and double helix-type tube (right)

The calculation results of three different simulation models at $0.1 \mathrm{~m} / \mathrm{s}$ velocity are shown in Figure 10, where the D10-T5-R50 model uses the original spiral helical tube, the D10-T5-R50-U model uses the U-type tube and the D10-T5-R50-D model uses the double helix-type tube. It can be seen from Figure 10 that the effect of heat transfer in the U-type structure is similar to that produced by the original type (ie spiral helical tube); that is, the U-type structure increases the complexity of the tube while the area of thermal conductivity provided by the U-type structure does not improve the heat transfer efficiency inside the tube. Moreover, compared with the calculation result of the D10-T5-R50 model, the average temperature produced by the double helix-type tube structure is improved by $1.17^{\circ} \mathrm{C}$ but at a cost of a pressure increase. As can be seen, the maximum pressure in the double helix-type tube is $2.08 \times 10^{3} \mathrm{~Pa}$ larger than that in the original type. As a result, the heat transfer effect in the original type of tube is comparable to those seen in the U-type and double helix-type tubes, while its structural complexity is much reduced. Hence, in this paper the original spiral helical tube was adopted.

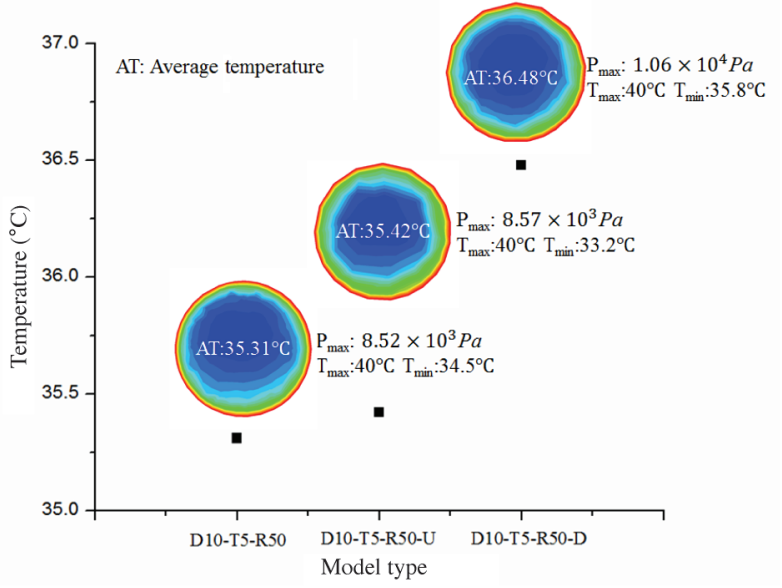

Figure 10. Calculated temperature results for different tube types

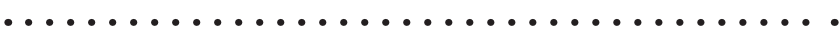

\subsubsection{Transfer of online measurement to ISO value}

Based on the above simulation results, a fitting function can be established to convert the online viscosity measurement to the ISO value. As shown in Figure 11, a fitting function between the outlet, inlet and ambient temperatures is first established. A linear relationship between the outlet temperature $T_{\text {out }}$, inlet temperature $T_{\text {in }}$ and ambient temperature $T_{\text {wall }}$ can be expressed as:

$$
T_{\text {out }}=0.3133 T_{\text {in }}+0.6874 T_{\text {wall }}
$$

That is, if the outlet and inlet temperatures are given, the ambient temperature can be calculated using Equation (3). The heater can then be controlled accordingly to ensure constant outlet temperature. For example, when the inlet temperature of the fluid $T_{\text {in }}$ is $12^{\circ} \mathrm{C}$, the controllable heater will control and maintain the ambient temperature $T_{\text {wall }}$ at $52.72^{\circ} \mathrm{C}$ to ensure the ISO standard of $40^{\circ} \mathrm{C}$ for the outlet temperature $T_{\text {out }}$. As a result, the viscositytemperature characteristics of the fluid can be obtained using the proposed device. Subsequently, the real-time viscosity measurement can be converted into the ISO value through looking up the viscosity-temperature characteristics.

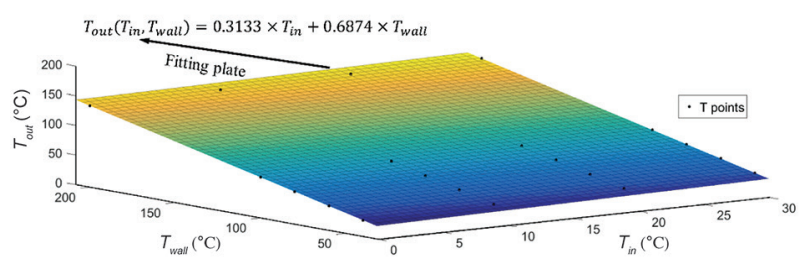

Figure 11. Relationship between outlet temperature, inlet temperature and environment temperature

\section{Conclusions}

This paper has proposed a new online viscosity measuring device that enables the conversion of real-time measurements into ISO standard values. The structural parameters have been optimised using factor analysis design. The proposed sensing device firstly establishes the viscosity-temperature characteristics of the measured fluid with the help of a cooling system and a controllable heater. Then, for online monitoring, the cooling system and the controllable heater are shut off. The real-time viscosity measurement is converted into an ISO value by data fitting using the viscosity-temperature characteristics. The main conclusions for this application include the following: (1) the determined tube diameter is $10 \mathrm{~mm}$, the spiral number is five and the spiral radius is $100 \mathrm{~mm}$; (2) in the 
optimisation of the thermal conductivity area in the flow tube, the length of the double helix-type tube increases; the efficiency of heat transfer is constant with a limited increase in tube length; however, a greater length increases the inlet pressure observably, which may influence the effect of laminar flow velocity; (3) the relationship between the average outlet temperature and the inlet and environmental temperatures is linear. In the future, a prototype of the proposed viscosity sensing device will be manufactured for online monitoring of the viscosity of lubricant oil in rotating machinery.

\section{Acknowledgements}

This work is supported by NSFC (Nos 51505475 and 51465026), Yunnan Science and Technology Plan Project (No 2017FB092), Hubei Key Laboratory of Power System Design and Test for Electrical Vehicle (HBUASEV2018F002) and Hubei Superior and Distinctive Discipline Group of Mechatronics and Automobiles (XKQ2018002). The authors also appreciate Kunming University of Science and Technology for providing the start-up funding as an academic innovation contest project for undergraduates.

\section{References}

1. A Glowacz, 'Fault diagnosis of single-phase induction motor based on acoustic signals', Mechanical Systems and Signal Processing, Vol 117, pp 65-80, February 2019.

2. A Glowacz, G Witold, G Zygfryd and K Jaroslaw, 'Early fault diagnosis of bearing and stator faults of the single-phase induction motor using acoustic signals', Measurement, Vol 113, pp 1-9, 2018.

3. M Mia, K Gupta, G Singh, G Królczyk and Y Pimenov, 'An approach to cleaner production for machining hardened steel using different cooling-lubrication conditions', Journal of Cleaner Production, Vol 187, pp 1069-1081, 2018.

4. M Shariq, S Madhulika, T Rupam, C Somnath, V Pedro, G Nenad and K Grzegorz, 'Optimisation and characterisation of friction surfaced coatings of ferrous alloys', Materials Testing, Vol 60, No 7-8, pp 707-718, 2018.

5. Y Su, Y Zhang, J Song and L Hu, 'Tribological behaviour and lubrication mechanism of self-lubricating ceramic/metal composites: the effect of matrix type on the friction and wear properties', Wear, Vol 372, pp 130-138, 2017.

6. G Meek, R Williams, D Thornton, P Knapp and S Cosser, 'F2E - ultra high-pressure distributed pump common rail system (No 2014-01-1440)', SAE Technical Paper, 2014.

7. S Shin and D Keum, 'Viscosity measurement of non-Newtonian fluid foods with a mass-detecting capillary viscometer', Journal of Food Engineering, Vol 58, No 1, pp 5-10, 2003.

8. Y Zhang, M He, R Xue, X Wang, Q Zhong and X Zhang, 'A new method for liquid viscosity measurements: inclined-tube viscometry', International Journal of Thermophysics, Vol 29, No 2, p 483, 2008.

9. J Camas-Anzueto, J Gómez-Pérez, R Meza-Gordillo, G Anzueto-Sánchez, M Pérez-Patricio, F López-Estrada, M Abud-Archila and C Ríos-Rojas, 'Measurement of the viscosity of biodiesel by using an optical viscometer', Flow Measurement and Instrumentation, Vol 54, pp 82-87, 2017.

10. D Zerkle, M Núñez and J Zucker, 'Molten composition B viscosity at elevated temperature', Journal of Energetic Materials, Vol 34, No 4, pp 368-383, 2016.

11. M Mustafaev, 'The theory of falling-hollow-cylinder viscometer', High Temperature, Vol 44, No 4, pp 633-636, 2006.

12. A Rowane, R Mallepally, B Bamgbade, M Newkirk, H Baled, W Burgess, I Gamwo, D Tapriyal, R Enick and M McHugh, 'Hightemperature, high-pressure viscosities and densities of toluene', Journal of Chemical Thermodynamics, Vol 115, pp 34-46, 2017.

13. I Lee, K Park and J Lee, 'Note: precision viscosity measurement using suspended microchannel resonators', Review of Scientific Instruments, Vol 83, No 11, p 116106, 2012.

14. A Pimentel-Rodas, L Galicia-Luna and J Castro-Arellano, 'Capillary viscometer and vibrating tube densimeter for simultaneous measurements up to $70 \mathrm{MPa}$ and $423 \mathrm{~K}$ ', Journal of Chemical \& Engineering Data, Vol 61, No 1, pp 45-55, 2015.

15. M Madan and D Mazumdar, 'Computational assessment of viscosity measurement in rotating viscometers through detailed numerical simulation', Metallurgical and Materials Transactions B, Vol 35, No 4, pp 805-809, 2004.

16. K Schumacher, J White and J Downey, 'Viscosities in the calcium-silicate slag system in the range of $1798 \mathrm{~K}$ to $1973 \mathrm{~K}$ $\left(1525^{\circ} \mathrm{C} \text { to } 1700^{\circ} \mathrm{C}\right)^{\prime}$, Metallurgical and Materials Transactions B, Vol 46, No 1, pp 119-124, 2015.

17. I Etchart, M Sullivan, J Jundt, C Harrison, A Goodwin and K Hsu, 'A comparison of both steady-state resonance and transient decay methods of determining viscosity with a vibrating wire viscometer: results for certified reference fluids for viscosity that are stagnant with viscosity between $(2.5$ and 66$) \mathrm{mPa} \cdot \mathrm{s}$ and flowing at volumetric flow rates below $50 \mathrm{~cm}^{3} \cdot \mathrm{s}^{-1}$ and viscosities less than $34 \mathrm{mPa} \cdot \mathrm{s}^{\prime}$, Journal of Chemical \& Engineering Data, Vol 53, No 8, pp 1691-1697, 2008.

18. F Janeiro, P Ramos, J Fareleira, J Diogo, D Máximo and F Caetano, 'Impedance spectroscopy of a vibrating wire for viscosity measurements', Proceedings of the 2010 IEEE Instrumentation \& Measurement Technology Conference (I2MTC), Austin, Texas, USA, pp 1067-1072, 3-6 May 2010.

19. J Diogo, F Caetano, J Fareleira, W Wakeham, C Afonso and C Marques, 'Viscosity measurements of the ionic liquid trihexyl (tetradecyl) phosphonium dicyanamide using the vibrating wire technique, Journal of Chemical \& Engineering Data, Vol 57, No 4, pp 1015-1025, 2012.

20. J Ma, X Huang, H Bae, Y Zheng, C Liu, M Zhao and M Yu, 'Liquid viscosity measurement using a vibrating flexure hinged structure and a fibre-optic sensor', IEEE Sensors Journal, Vol 16, No 13, pp 5249-5258, 2016.

21. P Lv, Z Yang, Z Hua, M Li, M Lin and Z Dong, 'Measurement of viscosity of liquid in micro-crevice', Flow Measurement \& Instrumentation, Vol 46, pp 72-79, 2015.

22. J Zambrano, M Sobrino, M Martín, M Villamañán, C Chamorro and J Segovia, 'Contributing to accurate high-pressure viscosity measurements: vibrating wire viscometer and falling body viscometer techniques', Journal of Chemical Thermodynamics, Vol 96, pp 104-116, 2016.

23. $\mathrm{X} \mathrm{Li}$ and $\mathrm{X}$ Zhao, 'Influences of temperature on measuring error of kinematic viscosity of space lubricant', Lubricating Oil, Vol 25, No 5, pp 57-60, 2010.

24. ISO 3448:1992, 'Industrial liquid lubricants - ISO viscosity classification', 1992.

25. Z Li, M Sheikholeslami, M Samandari and A Shafee, 'Nanofluid unsteady heat transfer in a porous energy storage enclosure in existence of Lorentz forces', International Journal of Heat and Mass Transfer, Vol 127, pp 914-926, 2018.

26. B Qu, Q Yang, Y Li, R Malekian and Z Li, 'A new concentration detection system for SF6/N2 mixture gas in extra/ultra highvoltage power transmission systems,' IEEE Sensors Journal, Vol 18, No 9, pp 3806-3812, 2018.

27. S Feng and $\mathrm{W} \mathrm{Li}$, 'An accurate and efficient algorithm for the simulation of fatigue crack growth based on XFEM and combined approximations', Applied Mathematical Modelling, Vol 55, pp 600-615, 2018.

28. S Feng, X Cui and A Li, 'Fast and efficient analysis of transient non-linear heat conduction problems using combined approximations (CA) method', International Journal of Heat and Mass Transfer, Vol 97, pp 638-644, 2016. 
Copyright of Insight: Non-Destructive Testing \& Condition Monitoring is the property of British Institute of Non-Destructive Testing and its content may not be copied or emailed to multiple sites or posted to a listserv without the copyright holder's express written permission. However, users may print, download, or email articles for individual use. 